\title{
Microalgae biotechnology multiple use of Chlorella sorokiniana
}

\author{
N.A. Politaeva, Y.A. Smyatskaya \& I.V. Dolbnya \\ Peter the Great St. Petersburg Polytechnic University, St. Petersburg, Russia \\ D.S. Sobgaida \\ Saratov State Medical University named after V.I. Razumovsky, Saratov, Russia
}

\begin{abstract}
This study is dedicated to realization closed biotechnology using Chlorella sorokiniana microalgae. It is a new source of valuable components for various kinds of industry and for obtaining energy such as biofuel and biogas. This technology includes several main stages: microalgae cultivation; extraction of lipids, pigments, pectic substances and carotenoids from the biomass; creation sorption materials based on residual biomass of microalgae for water treatment; using residual biomass and saturated sorbents as a fuel, as a co-substrate for organic waste fermentation and as fertilizers. It is shown that the realization of presented biotechnology allows to use each product on every step of the technology.
\end{abstract}

\section{INTRODUCTION}

Nowadays, biomass of different microalga species is used widely in various industries such as: the ecological industry, in water purification, biotechnology, pharmacy, in the food industry and for biofuel production. Green microalgae grow fast. They do not require large soil territories like in the case of conventional food crops and they can be cultivated in closed or open cultivation systems (cultivators and photobioreactors) (Azad, 2019). And they need provision of light, nutrients and aeration. Microalgae is a source of many valuable components such as: lipids, proteins, pigments, carotenoids, pectic substances. These components are extracted from the biomass and can be used in different fields of production.

One of the main ecological problems is water pollution by organic and inorganic substances. Fresh water is widely used in different fields of industry, for agricultural and domestic needs; after technological processes wastewater is formed. They contain various kinds of pollutants including suspended particles and dissolved ones. Often, they are toxic, for example heavy metal ions (Afroze, 2018). Microalgae are good sorption materials for water purification (Abdel-Raouf, 2012). It is possible to grow them with the use of wastewater as a nutrient medium or to use their residual biomass which is formed after extraction valuable components.

Sorption is the one of the effective methods for water treatment. It is a process of concentration pollutants on the surface or the porous area of the material (sorbent). If it occurs on the surface of solid material, the adsorption arises. If liquid or gas phase is used as a sorbent, and in this case, contaminants are concentrated in the volume of the phase, the absorption occurs (Gregg, 1982; Dąbrowski, 2001). At the same time, sorption is a complicated method. Therefore, it is important to develop research in this field, accumulate new knowledge, find new materials which can be used as sorbents, establish modern modification methods for sorption materials creation. Herewith, technologies which are invented for a solution of some problems have not to be the reason of other difficulties, it is important to apply them in a complex way.

Thus, innovative biotechnology multiple use of Chlorella sorokiniana microalgae was developed. It includes stages from biomass cultivation, extraction of pigments, lipids and pectic substances, creation sorption materials based on residual biomass for water treatment, and 
end up with biogas production by organic waste fermentation with residual biomass and saturated sorbents as co-substrate. The realization of this biotechnology allows to use of each component on every step and totally avoid waste accumulation, because all materials are considered as the resources.

\section{LITERATURE REVIEW}

\subsection{Microalgae biomass and its cultivation}

Microalgae are cultivated in cultivators and photobioreactors with different constructions; they can be closed or open, Figure 1.

All cultivation technics are divided into two categories: the first one is laboratory conditions and a controlled environment, Figure 2; the second one is outdoor conditions which allow to produce large amount of biomass (Vonshak, 1985; Brennan, 2010). Each type of this technic has advantages and disadvantages. The closed system prevents contamination by other microalgae species and some pollutants, but the open pond should be controlled to avoid such problems. Some construction of the cultivator has a special electro and mechanical providing which allows to move panels with cultivators in the direction of sunlight, Figure $1 \mathrm{~b}$.

Microalgae are living microorganisms, for their growth they need in nutrients medium supply. The nutrients medium should consist of following elements: carbon, hydrogen, oxygen, calcium, potassium, magnesium, nitrogen, iron, phosphorus, sulfur, and copper, manganese, zinc or selenium as trace elements. But three elements such as carbon, nitrogen and
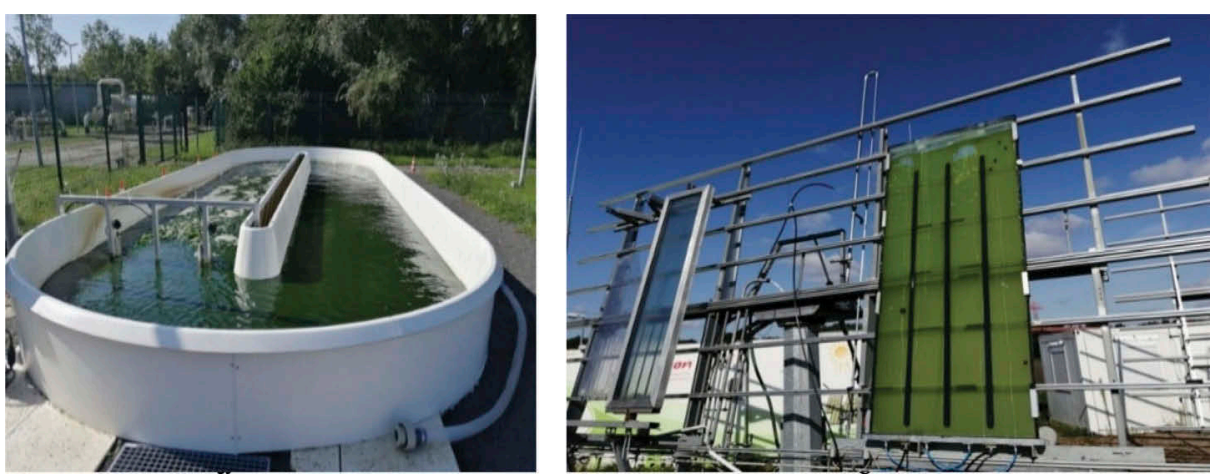

Figure 1. Types of cultivation systems (outdoor conditions): $a-$ open raceway pond; $b$ - closed photobioreactor.
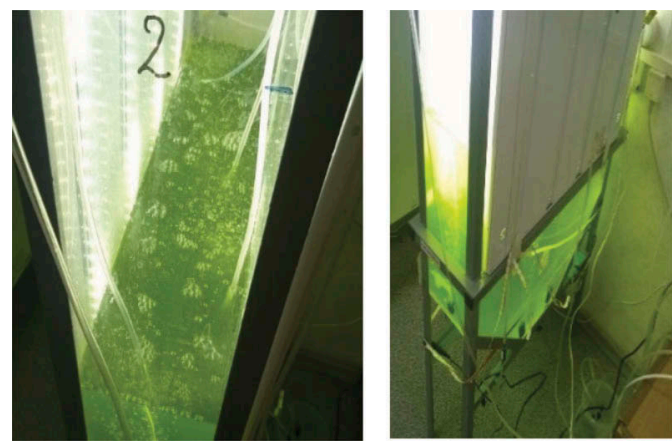

Figure 2. Microalgae cultivation in laboratory conditions (closed photobioreactors). 
phosphorus are the most important for growth (Geada, 2017; Richmond, 2013). The use of additional external physical actions (e.g. laser radiation, magnetic field) allows to maximize biomass growth in the shortest time (Politaeva, 2018; Smyatskaya, 2019).

Microalgae represent green carbon as an alternative to fossil carbon (fuels); these microorganisms capable to produce biomass enriched with valuable components using sun energy. As all green plants they absorb $\mathrm{CO}_{2}$ and convert it into $\mathrm{O}_{2}$. Thus, they provide decrease of $\mathrm{CO}_{2}$ concentration in the air and take part in minimization of global warming. So, the use of microalgae as a new source of energy has a lot of advantages and perspectives (Geada, 2017).

Chlorella sorokiniana is widely used to obtain the biomass containing lipids and proteins. It is a singlecelled green microalga characterized by its small size $(2-10 \mu \mathrm{m}$ in diameter $)$ and high division rate (1division every 17 to 24 hours). It is non-flagellated and has thick cell wall. These microalgae contain high amounts of valuable compounds: $40 \%$ protein, 30-38 \% carbohydrate, 18-22\% lipid, pigments (lutein), etc. (Niccolai, 2019; De Andrade, 2017).

\subsection{Wastewater treatment}

Water contamination is the main ecological problem in the world. Industry and agriculture use a large amount of fresh water for production needs. And after technological processes wastewater are formed, which include in their composition various kinds of substances specific for certain activity. In the most cases these substances are hazardous even in small concentrations and have the ability to accumulate in body tissues of living organisms and then can reach the human body by movement along the food chain. It is extremely important to apply special technological methods and equipment to get purified water. Even for now the planet has such territories with lack of fresh water and for some people it is very hard to have it in a sufficient amount.

Water treatment technology consists from following methods: physical, chemical, physicochemical, biological. The choice of one method or another or their group depends on initial water contamination and purposes of its further usage. Wastewater containing suspended substances go through a stage of pretreatment; during this process large particles such as wood, rags, fecal material and others are removed. Then sewage flow in sedimentation tanks, where sedimentation of settleable solids occurs by gravity. Water prepared in this way is directed on a stage of more deep sorption purification where dissolved impurities are removed. At the end of the process purified water flows on biological treatment, then its disinfection is curried out and after this water can be used again.

Microalgae widely used in the process of water purification. As they capable to actively accumulate biomass by transformation of sun energy it is possible to use of wastewater as nutrient medium for their growth (De la Noüe, 1988; Abdel-Raouf, 2012).

Algae have a good accumulation ability in relation to different heavy metal ions: $\mathrm{Cu}^{2+}, \mathrm{Pb}^{2+}$, $\mathrm{Cr}^{3+}, \mathrm{Ni}^{2+}, \mathrm{Cd}^{2+}, \mathrm{Co}^{2+}, \mathrm{Fe}^{2+}, \mathrm{Mn}^{2+}, \mathrm{Zn}^{2+}$. And these elements are included in the biological process of microalgae growth, at the same time metal detoxication occurs. Different mechanisms lead to reducing heavy metals concentration by microalgae. It depends on the algae species, the type of metal ion and its valency, the condition of aqueous solution and the state of algae cells, which can be living or nonliving (Abdel-Raouf, 2012). And it is possible to use a residual biomass of microalgae which is formed after extraction of valuable components for water treatment as sorption materials.

\subsection{Sorption process and sorption materials}

Sorption is surface phenomenon when accumulation of substances near an interface takes place. This process may be defined as partitioning of chemical species between bulk phase and interface. It can be a contact of such systems as solid-liquid, liquid-liquid, liquid-gas and solid-gas. The possibility of change in concentration of a given substance at the interface in comparison with bulk phase underlies many directions of technology including purification nature environments such as water, gas, soil (Dąbrowski, 2001; Bajpai, 1999). 
Sorption is the general determination of the process, but when this phenomenon caries out on a surface or porous space of solid phase, adsorption occurs. But in the case of concentration of the substances in the volume of liquid or gas phase, absorption arises. It is important to distinguish these specific terms. Also, sorption has different types; when physical interactions caused by Van der Waals forces take place, the process is called physical sorption; when interactions between two phases are caused by chemical mechanisms with formation of new substances, in this case sorption has the chemical type.

Now, a lot of different materials are used as sorbents for water treatment. The most famous is activated carbon. This material is widely used as adsorbent for the removal of different kinds of contaminants, which have organic and inorganic origin. Activated carbon has good sorption properties, high values of adsorption capacity and surface area (Rodriguez-Reinoso, 2016). But it also has some disadvantages in application as difficulties with regeneration after sorption and this is expansive material. Because of it, there are many research dedicated to development of new materials with the same properties like activated carbon has; and now in the most cases researches pay attention on the use of waste to create sorption materials based on them. It can be agricultural waste such as wheat and millet husk, sunflower husk, nuts shells, rice straw; also, it can be chitosan, zeolites, waste of food production and other kinds of industry (Crini, 2018; Jagruti, 2015; Khalil, 2018; Politaeva, 2019a). Due to the use of waste for these purposes another one urgent ecological problem related to this can be solved. As it was previously mentioned the biomass of microalgae is the good sorbent for many substances in aqueous solutions; and it is possible to use residual biomass for water purification, because of the composition of this natural material consisting of cellulose, hemicellulose, lignin, etc. On practice in the most cases row materials have such sorption characteristics which are not so good enough. Therefore, various kinds of modification are applied to improve sorption properties (thermal and chemical modification). In order to increase the sorption capacity composite sorption materials can be created with different composition. As a binder substance chitosan can be used in obtaining of granulated sorbents. It is a biopolymer and it has good sorption properties in relation to contaminants in water solutions. And in water treatment technology it is also used as a sorbent, but because of its high cost, chitosan doesn't find a wide application. But residual microalgae biomass included in the composition with chitosan increases sorption characteristics of a new created granulated sorbent and leads to improvement of chitosan resistance to dissolution in acid environment.

\subsection{Biogas production with the use of microalgae}

Another advantage to develop the biotechnology of microalgae treatment is biogas production. Nowadays it is third generation biofuel. Microalgae produce an oil that can be refined into biodiesel. It is a renewable one and it includes methane, carbon dioxide and biohydrogen. The grow rate of microalgae is very high; large land territories for biomass production is not needed. Because of it, microalgae as a source of energy is more profitable in comparison with materials used as a basis for first and second generation fuels. In general, the process of biogas production from microalgae biomass is commercially viable, when firstly all by-products are extracted from the initial biomass. And after that for the purposes of biogas production the residual biomass is applied (Alam, 2015; Brennan, 2010; Azad, 2019; Tang, 2016). Converting the biomass into biogas components (methane, hydrogen and $\mathrm{CO}_{2}$ ) carries out at anaerobically digested conditions (Chusov, 2019). Thus, the complex use of microalgae potential through all stages of the biotechnology allows to get a lot of useful by-products, new materials and energy.

During implementation of international project entitled «Development and implementation of innovative biotechnologies for treatment of microalgae Chlorella sorokiniana and the duckweed Lemna minor» a closed loop biotechnology using Chlorella sorokiniana microalgae biomass has been developed. It includes following stages: cultivation microalgae in bioreactors; harvesting; extraction lipids and fatty acids, and pigments; obtaining sorption materials based on residual biomass for water treatment; producing biogas by fermentation of used sorbents and other waste which are formed. 


\section{MATERIALS AND METHODS}

\subsection{Cultivation of Chlorella sorokiniana microalgae in laboratory conditions and its harvest}

Chlorella sorokiniana microalgae were cultivated in closed photobioreactors which are presented in Figure 2. For its growth nutrition medium was prepared based on modified Hoagland solution including composition of macro- and micronutrients, which are important for microalgae cell formation (Richmond, 2004). Specific growth conditions were provided such as illumination of photobioreactors using fluoriscence lamps with duration 18 hours per day in the regime of day/night with constant aeration by air. This aeration was conducted by bubbling Xilong AP-003 device ( $5 \mathrm{~W}, 2 \mathrm{Kh} 2,5 \mathrm{l} / \mathrm{mines})$. The optical density of the biomass from the beginning of the cultivation was measured by spectrophotometer Shimadzu UV-1280 at $\lambda=750 \mathrm{~nm}$. It allows to control cells culture accumulation. And after 10 days the biomass growth reaches maximum amounts at the stationary phase of the growth (Politaeva, 2018b).

The next step after cultivation is harvest. Biomass concentration was carried out by microfiltration through membrane filters or by centrifugation. After this step, the biomass was dried by freeze-drying.

\subsection{Extraction of valuable components}

Chlorella sorokiniana biomass is the source of many valuable components such as: lipids including fatty acids which can be used for Omega - 3 and biofuel production; carotenoids which are widely used in pharmaceutic industry; green pigments which can be used in the fields of cosmetology and in the food industry as dietary pigments; pectic substances which are useful ingredients in the food production. The extraction of lipids and this process are described in following scientific article (Politaeva, 2019b).

\subsection{Sorption material for water treatment based on residual biomass and chitosan}

After the extraction of valuable components, a residual biomass is formed. It is a kind of waste, but at the same time it is a material with useful properties. Therefore, it can be used for obtaining sorption material for water treatment from heavy metal ions. It is known that these substances are toxic and are often contained in wastewater, so it is relevant to look for new methods to remove these heavy metal ions and get purified water. So, the technology of obtaining sorption material based on carbonized residual biomass and chitosan as a binder substance consists of following steps. First, the residual biomass is carbonized at high temperatures in order to be activated. The second step is the dissolution of chitosan in a $3 \%$ solution of acetic acid. Then all components are mixed and the next, the granulation step is carried out by the addition of the mixture drop by drop to a $5 \%$ solution of sodium hydroxide. The granules are then left to soak in this solution for 24 hours. Then the granules are washed using distilled water until reaching neutral $\mathrm{pH}$ values. After this, the material is by ambient air drying.

The determination of the sorption properties of the obtained sorbent was conducted. Sorption isotherms were experimentally obtained. The initial and equilibrium concentrations of heavy metal ions in the modal water solution have been measured with the use of TA-Lab device (Russia, LLC Research production enterprise Tom'analit) which work based on inversion voltammetric method of analysis, using standard Russian method Environmental Protection Regulation 14.1:2:4.222-06. The inaccuracy of measuring technique is $25 \%$. Experimental conditions of purification model water solutions consisted of $\mathrm{Zn}^{2+}, \mathrm{Cd}^{2+}$ and $\mathrm{Cu}^{2+}$ ions: $\mathrm{m}_{\text {sorbent }} / \mathrm{V}_{\text {solution }}=$ $2 \mathrm{~g} / \mathrm{l} ; \mathrm{t}_{\text {sorption }}=24$ hours; $\mathrm{T}=20 \pm 2{ }^{\circ} \mathrm{C} ; \mathrm{pH}=4.0 \pm 0.2$. The experiment accuracy is within the limits of 5-10\%. The sorption capacity was calculated using Equation 1:

$$
q=\frac{\left(C_{i}-C_{e}\right) \cdot V}{m}
$$


where $\mathrm{C}_{\mathrm{i}}$ and $\mathrm{C}_{\mathrm{e}}$ - initial and equilibrium concentrations of heavy metal ions (mmol/l); V solution volume (1); and $\mathrm{m}$ - mass of the sorbent (g).

To describe sorption process two sorption models were applied: Lengmuir (Equation 2) and Freundlich (Equation 3) isotherm models. Equation 2 is a linearized form of Lengmuir sorption model (Ayawei, 2017).

$$
\frac{1}{q}=\frac{1}{q_{\max }}+\frac{1}{K q_{\max } C_{e}}
$$

where $\mathrm{q}$ - sorption capacity $(\mathrm{mmol} / \mathrm{g}) ; \mathrm{q}_{\max }$ - maximum sorption capacity of the sorbent ( $\mathrm{mmol} / \mathrm{g}) ; \mathrm{C}_{\mathrm{e}}$ - equilibrium heavy metal ions concentration in the solution (mmol/l); $\mathrm{K}$ - Langmuir constant which notices on sorption rate and it is also a coefficient or constant of sorption equilibrium $(1 / \mathrm{mmol})$.

Equation 3 is a logarithmic form of Freundlich sorption model (Ayawei, 2017).

$$
\log q=\log K+1 / n \log C_{e}
$$

where $\mathrm{q}$ - sorption capacity (mmol/g); $\mathrm{K}$ and $\mathrm{n}$ - constants of Freundlich sorption model; $\mathrm{C}_{\mathrm{e}}-$ equilibrium heavy metal ions concentration ( $\left.\mathrm{mmol} / \mathrm{l}\right)$.

In order to establish sorption character (physical or chemical mechanism) Gibbs free energy has been calculated by Equation 4 (Gautam, 2016):

$$
\Delta G=-R \cdot T \cdot \ln K
$$

where $\mathrm{R}$ - universal gas constant which equal to $8,314(\mathrm{~J} / \mathrm{mol} \cdot \mathrm{K})$; $\mathrm{T}$ - absolute temperature (K); K - coefficient or constant of sorption equilibrium $(1 / \mathrm{mmol})$.

If $\Delta \mathrm{G}<0$, there is an absence of energy consumption during sorption process, therefore the physical mechanism of interaction between sorbate and sorbent is observed. In that case if $\Delta \mathrm{G}>0$, chemisorption caries out, some amounts of energy are expended on interactions between dissolved substance with sorbent with formation of tough chemical bond or new compound. If $\Delta \mathrm{G}=0$, a system is in equilibrium. The results are presented in Table 3 .

Microstructure of obtained sorption material was identified by scanning electron microscopy with the use of JSM 7001F (JEOL, Japan) equipment. The graphs of the sorption isotherms and all data of the experiment were statistically calculated with the help of Microsoft Office Excel 2019 software (Politaeva, 2019b).

The process of biogas production using Chlorella sorokiniana microalgae residual biomass is presented and described in detail in following article (Chusov, 2019).

\section{RESULTS AND DISCUSSION}

Obtained sorption material (carbonized residual biomass + chitosan $(\mathrm{CRB}+\mathrm{Chitosan})$ ) has a shape of granules and it is presented in Figure 3a. The sorbent microstructure (1000) is shown on Figure 3b.

The structure of the material has roughness, porous and cracks which determine the sorption of contaminants from aqueous solution. Studying the surface of the sorbent it is possible to presume the physical adsorption. To establish the sorption mechanism more accurately sorption isotherms have been obtained by conducting of the bunch of the experiments with certain conditions, Figure 4. They have the shape of Langmuir type of isotherm or the first type of isotherm of BET classification (Abebe, 2018). It is the first sign of sorption conducted by physical mechanisms. After mathematical conversion the isotherms were linearized. The constants of Langmuir and Freundlich sorption models have been graphically determined. A suitability of the isotherms in relation to studied sorption models was established by values of correlation coefficient ( $\mathrm{r}$ ) and approximation coefficient $\left(\mathrm{R}^{2}\right)$, Table 1 and Table 2 . If they 


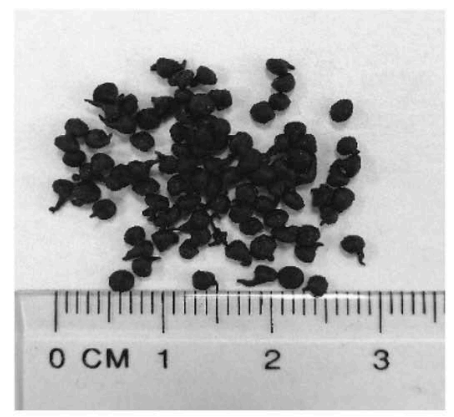

a

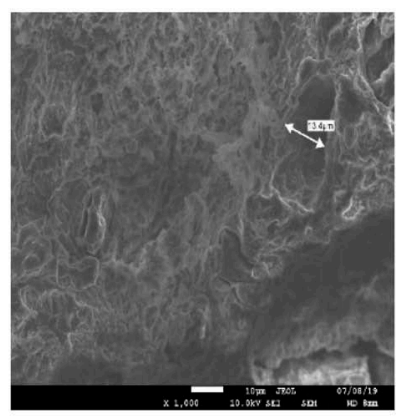

b

Figure 3. Sorption material CRB+Chitosan.

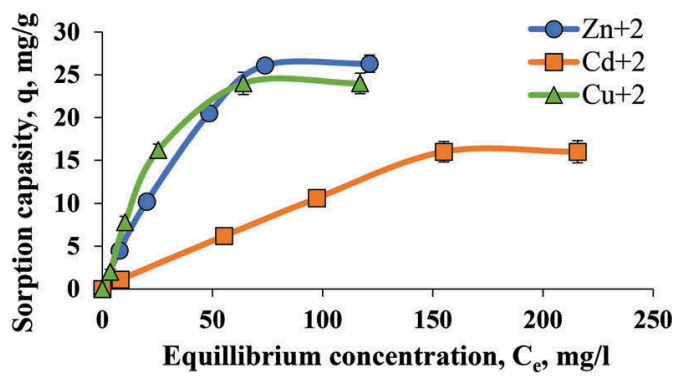

Figure 4. Sorption isotherms.

Table 1. Application of Langmuir sorption model.

\begin{tabular}{lllllll}
\hline Sorbent & Heavy metal ions & $\mathrm{q}_{\max }, \mathrm{mmol} / \mathrm{g}$ & $\operatorname{tg} \alpha=1 / \mathrm{q}_{\max }$ & $\mathrm{K}, 1 / \mathrm{mmol}$ & $\mathrm{r}$ & $\mathrm{R}^{2}$ \\
\hline CRP+Chitosan & $\mathrm{Zn}^{+2}$ & 0.78 & 1.28 & 0.8 & 0.999 & 0.998 \\
& $\mathrm{Cd}^{+2}$ & 0.12 & 8.67 & 1.4 & 0.995 & 0.871 \\
& $\mathrm{Cu}^{+2}$ & 7.23 & 0.14 & 0.1 & 0.991 & 0.981 \\
\hline
\end{tabular}

Table 2. Application of Freundlich sorption model.

\begin{tabular}{lllllll}
\hline Sorbent & Heavy metal ions & $\mathrm{K}$ & $1 / \mathrm{n}$ & $\mathrm{n}$ & $\mathrm{r}$ & $\mathrm{R}^{2}$ \\
\hline CRP+Chitosan & $\mathrm{Zn}^{+2}$ & 0.33 & 0.682 & 1.5 & 0.978 & 0.956 \\
& $\mathrm{Cd}^{+2}$ & 0.10 & 0.860 & 1.2 & 0.994 & 0.989 \\
& $\mathrm{Cu}^{+2}$ & 0.35 & 0.712 & 1.4 & 0.949 & 0.900 \\
\hline
\end{tabular}

Table 3. Gibbs free energy and type of sorption.

\begin{tabular}{llll}
\hline Sorbent & Heavy metal ions & $\Delta \mathrm{G}, \mathrm{kJ} / \mathrm{mol}$ & Type of sorption \\
\hline CRP+Chitosan & $\mathrm{Zn}^{+2}$ & 0.5 & Chemisorption \\
& $\mathrm{Cd}^{+2}$ & -0.8 & Physical sorption \\
& $\mathrm{Cu}^{+2}$ & 5.6 & Chemisorption \\
\hline
\end{tabular}




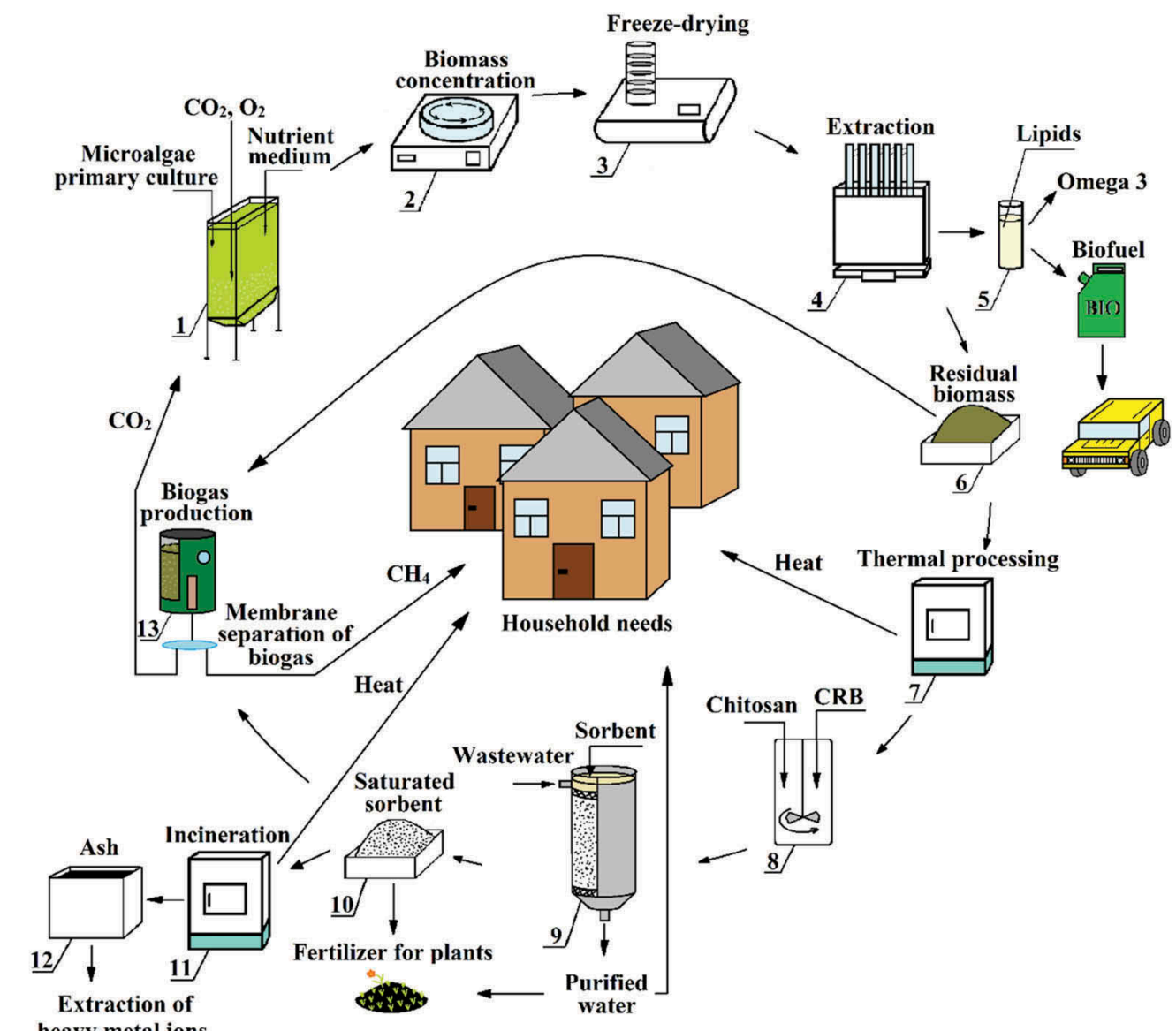

heavy metal ions and rare earth elements

"CRB - carbonized residual biomass

Figure 5. Microalgae biotechnology multiple use of Chlorella sorokiniana (general scheme).

1 - photobioreactor; 2 - centrifuge; 3 - freeze-dryer; 4 - Soxhlet extractor; 5 - lipids extracted from mi-croalgae; 6 - storage tank for residual biomass; 7, 11 - muffle furnace; 8 - mixing apparatus; 9 - appa-ratus for water treatment (adsorber); 10 - storage tank for saturated sorbent; 12 - storage tank for ash; 13 - bioreactor.

are close to 1.0, experimental results are described in an appropriate way, and this or that isotherm refers to one of two studied models or even both of them.

Thus, the results indicate the possibility to use obtained sorption material in the fields of industry where wastewater are formed containing heavy metal ions including the mining industry.

After a sorption process saturated sorbents can be utilized by three ways such as: use it as a fuel, as a co-substrate for organic waste fermentation and as fertilizers.

The general scheme of cyclic ecotechnology is presented on Figure 5. It includes all steps which have been reviewed previously. The main idea is the complex use of each component on every step of the technology.

\section{CONCLUSIONS}

To conclude, Chlorella sorokiniana biomass presents several promising applications. It is the source of valuable components which can be used in different fields of industry. Sorption material based on residual biomass and chitosan have been proved effective for water 
purification from heavy metal ions. The realization of this closed loop biotechnology using microalgae biomass allows to get new resources, products, materials, energy, that can be used in a complex way.

\section{ACKNOWLEDGEMENTS}

The research was performed within the implementation of Federal Target Program for Research and Development in Priority Areas of the Russian Scientific and Technological Complex for 2014 - 2020, the project «Development and implementation of innovative biotechnologies for treatment of microalgae Chlorella sorokiniana and the duckweed Lemna minor» (Agreement № 14.587.21.0038 of 17.07.2017), the unique project identifier is RFMEFI58717X0038.

\section{REFERENCES}

Abdel-Raouf, N., Al-Homaidan, A.A. \& Ibraheem, I.B.M. 2012. Microalgae and wastewater treatment. Saudi Journal of Biological Sciences 19(3): 257-275.

Abebe, B., Ananda Murthy, H.C. \& Amare, E. 2018. Summary on Adsorption and Photocatalysis for Pollutant Remediation: Mini Review. Journal of Encapsulation and Adsorption Sciences 8: 225-255.

Alam, F., Mobin, S. \& Chowdhury, H. 2015. Third generation biofuel from Algae. 6th BSME International Conference on Thermal Engineering (ICTE 2014); Procedia Engineering 105: 763-768.

Afroze, S. \& Kanti Sen, T. 2018. A Review on Heavy Metal Ions and Dye Adsorption from Water by Agricultural Solid Waste Adsorbents. Water, Air \& Soil Pollution 229:225.

Ayawei, N., Ebelegi, A.N. \& Wankasi, D. 2017. Modelling and Interpretation of Adsorption Isotherms: Review Article. Hindawi Journal of Chemistry vol. 2017: 11 pages.

Azad, K. 2019. Advances in eco-fuels for a sustainable environment. Woodhead publishing series in energy. Elsivier.

Bajpai, A.K. \& Rajpoot, M. 1999. Adsorption Techniques - A Review. Journal of Scientific \& Industrial Research 58: 844-860.

Brennan, L. \& Owende, P. 2010. Biofuels from microalgae - A review of technologies for production, processing, and extractions of biofuels and co-products. Renewable and Sustainable Energy Reviews 14: $557-577$.

Chusov, A. et al. 2019. Determination of biogas potential of residual biomass of microalgae Chlorella sorokiniana. IOP Conf. Series: Earth and Environmental Science 403012225.

Crini, G. \& Litchfouse, E. 2018. Green adsorbents for pollutant removal: Fundamentals and Design. Environmental chemistry for a sustainable world. Springer.

Dąbrowski, A. 2001. Adsorption from theory to practice. Advances in Colloid and Interface Science 93: $135-224$.

De Andrade, C.J. \& De Andrade, L.M. 2017. An overview on the application of genus Chlorella in biotechnological processes. Journal of Advanced Research in Biotechnology 2(1): 1-9.

De la Noüe, J. \& De Pauw, N. 1988. The potential of microalgal biotechnology. A review of production and uses of microalgae. Biotechnol. Adv. 6: 725-770.

Gautam, R.K. \& Chattopadhyaya, M.C. 2016. Kinetics and Equilibrium Isotherm Modeling: Graphene-Based Nanomaterials for the Removal of Heavy Metals From Water: Chapter 5. Nanomaterials for Wastewater Remediation: 79-109.

Geada, P. et al. 2017. Microalgal Biomass Cultivation: Chapter 13. Algal Green Chemistry: 257-284.

Gregg, S.J. \& Sing, S.W. 1982. Adsorption, Surface Area and Porosity. London: Academic Press.

Jadava, J.N., Maindb, S.D. \& Bhaleraoa, S.A. 2015. Competitive biosorption of lead (II) ions from aqueous solutions onto Terminalia Catappa l. leaves as a cost effective biosorbent. Octa Journal of Environmental Research 3(1): 067-079.

Khalil, A., Sergeevich N. \& Borisova, V. 2018. Removal of ammonium from fish farms by biochar obtained from rice straw: Isotherm and kinetic studies for ammonium adsorption. Adsorption Science and Technology 36(5-6): 1294-1309.

Niccolai, A. et al. 2019. Microalgae of interest as food source: Biochemical composition and digestibility. Algal Research 42101617.

Politaeva, N. et al. 2018a. Effect of laser radiation on the cultivation rate of the microalga Chlorella sorokiniana as a source of biofuel. IOP Conf. Series: Earth and Environmental Science 115012001. 
Politaeva, N. et al. 2018b. Chlorella Microalga Biomass Cultivation for Obtaining Energy in Climatic Conditions of St. Petersburg. V. Murgul and Z. Popovic (eds.), International Scientific Conference Energy Management of Municipal Transportation Facilities and Transport EMMFT 2017, Advances in Intelligent Systems and Computing 692: 555-562.

Politaeva, N. et al. 2019a. Research of $\mathrm{pH}$ influence on sorption properties of sorbents on a basis of residual biomass of microalgae Chlorella sorokiniana and duckweed Lemna minor. E3S Web of Conferences 12401050.

Politaeva, N., Smyatskaya, Yu. \& Toumi, A. 2019b. Influence of SHF Treatment on Lipid Output from Microalga Chlorella sorokiniana. IOP Conference Series: Earth and Environmental Science 272032056.

Richmond, A. 2013. Biological principles of mass cultivation of photoautotrophic microalgae: Chapter 11. A. Richmond, Q. Hu (eds.), Handbook of Microalgal Culture. Oxford: John Wiley \& Sons.

Richmond, A. 2004. Handbook of Microalgal Culture: Biotechnology and Applied Phycology. Hoboken: Blackwell Science.

Rodriguez-Reinoso, F. \& Silvestre-Albero, J. 2016. Activated Carbon and Adsorption. Reference Module in Materials Science and Materials Engineering. Elsivier.

Smyatskaya, Y.A. et al. 2019. Study of chemical composition and properties of biomass of Chlorella sorokiniana under influence of different physical factors. Izvestiya Vysshikh Uchebnykh Zavedenii, Seria Khimia i Khimicheskaya Tekhnologiya 62(2): 72-78.

Tang, Y. et al. 2016. Microalgae as a feedstock for biofuel precursors and value-added products: green fuels and golden opportunities. BioResources 11(1): 2850-2885.

Vonshak, A. 1985. Micro-algae: laboratory growth techniques and outdoor biomass production: Chapter 15. Techniques in bioproductivity and photosynthesis: 188-200. 